\title{
Modeling of the Global Daily Horizontal Solar Radiation Data over Togo
}

\author{
Yendoubé Lare $^{1 *}$, Kanlanféi Sambiani1,2, Kokou Amega ${ }^{1,2}$, Moyème Kabe ${ }^{1}$ \\ ${ }^{1}$ Laboratoire sur l'Energie Solaire, Département de Physique, Université de Lomé, Lomé, Togo \\ ${ }^{2}$ West African Science Service Centre on Climate Change and Adapted Land Use (Wascal), University Abdou Moumouni of \\ Niamey, Niamey, Niger \\ Email: *yenlare@univ-lome.tg, *yenlare@yahoo.fr
}

How to cite this paper: Lare, Y., Sambiani, K., Amega, K. and Kabe, M. (2021) Modeling of the Global Daily Horizontal Solar Radiation Data over Togo. Energy and Power Engineering, 13, 403-412.

https://doi.org/10.4236/epe.2021.1312028

Received: October 18, 2021

Accepted: December 11, 2021

Published: December 14, 2021

Copyright $\odot 2021$ by author(s) and Scientific Research Publishing Inc. This work is licensed under the Creative Commons Attribution International License (CC BY 4.0).

http://creativecommons.org/licenses/by/4.0/

\begin{abstract}
Solar photovoltaic appears to be the most interesting renewable energy in developing countries where its deposit is abundant. Unfortunately, the lack of precise knowledge of solar radiation deposit and its limited data hinder optimal exploitation of solar installations. This study presents a performing model for daily global horizontal solar radiation for the five regional capitals in Togo: Lomé, Atakpamé, Sokodé, Kara and Dapaong. The data used for the study were obtained from the General Directorate of National Meteorology of Togo, for five years. The model developed combines linear and nonlinear methods with harmonic and exponential terms taking into account climatological parameters such as location latitude, daily relative humidity, daily ratio of sunshine duration and daily mean temperature. Statistical errors of the model were compared to those of two previous models elaborated for Togo and Nigeria. The results showed that the model is more efficient to predict global horizontal solar radiation over the five main cities in Togo. The comparison of estimated data and measured ones showed a good agreement between them.
\end{abstract}

\section{Keywords}

Horizontal Solar Radiation, Modeling, Non-Linear Regression, Statistical Errors

\section{Introduction}

Energy access and environmental issues have made research on the development and mastery of renewable energy technologies more than urgent today. Among the various renewable energy technologies, solar photovoltaic appears to be one of the most interesting, particularly in developing countries where access to 
energy is still relatively low while the solar deposit is abundant. Among other difficulties which often hinder optimal exploitation of solar installations, we can cite that related to the precise knowledge of the deposit. Indeed, the potential of solar applications and the accurate prediction of their performance and behaviour at a given site depend on the precise knowledge of the radiation data at that site. Unfortunately, in some countries, especially in developing ones, solar radiation is not always measured in many parts because of the cost of the entire data collection process [1] [2] [3]. Hence, the need to develop models to estimate, by extrapolation, solar radiation for the locations where there is no measuring equipment installed. In this context, several models using climatic weather parameters have been developed towards the world. Angstrom's model [4] and adjustment given by Prescott [5] afford a correlation between the global horizontal solar radiation and the relative sunshine hours. In Africa, among others, the estimation of the global solar radiation on the horizontal surface have been made with numerous empirical models in many countries such as Egypt [6] [7], Nigeria [8], Sudan [9] and Lesotho [10], where the models were often modified to correlate different geographic and meteorological parameters. In the same way, Ajayi et al. [11] focused on a new regression model taking some geographic and meteorological parameters for the whole of Nigeria; consequently, they carry out a good agreement within the measured data and computed results with minimum error. Likewise, Amou et al. [12] presented work on the linear and exponential model in order to predict the global horizontal solar radiation of many cities in Togo, thus parameters like relative humidity and mean daily temperature were used. The performance of these empirical models showed that only a few give less than $10 \%$ of relative error between simulated and measured values [13] [14]. Amou et al. [15], attempt also for forecasting Togo's potential solar radiation maps with the Multilayer Perceptron (MLP) across to artificial neural network (ANN) who depends on three parameters such as latitude, relative humidity and temperature. In view of these previous studies, the statistical errors of which are relatively high, it appears necessary to work on the development of more efficient models in order to be able to generate more precise solar irradiation data for all of Togo. It is in this spirit that this study was undertaken.

In this study, we focused on improving the performance of the nonlinear regression model taking into account parameters such as latitude, number of days, relative humidity, daily mean temperature, and sunshine duration. The model allowed us to establish the available daily solar global horizontal radiation data of many cities in Togo and reach out the best statistical regression factors for validation.

\section{Methodology}

\subsection{Study Area}

The five regional capitals, which are subject of our study, are presented in Figure 1. As can be seen, these cities are distributed over the length of the country and therefore correctly represent the entire climate of the country. 


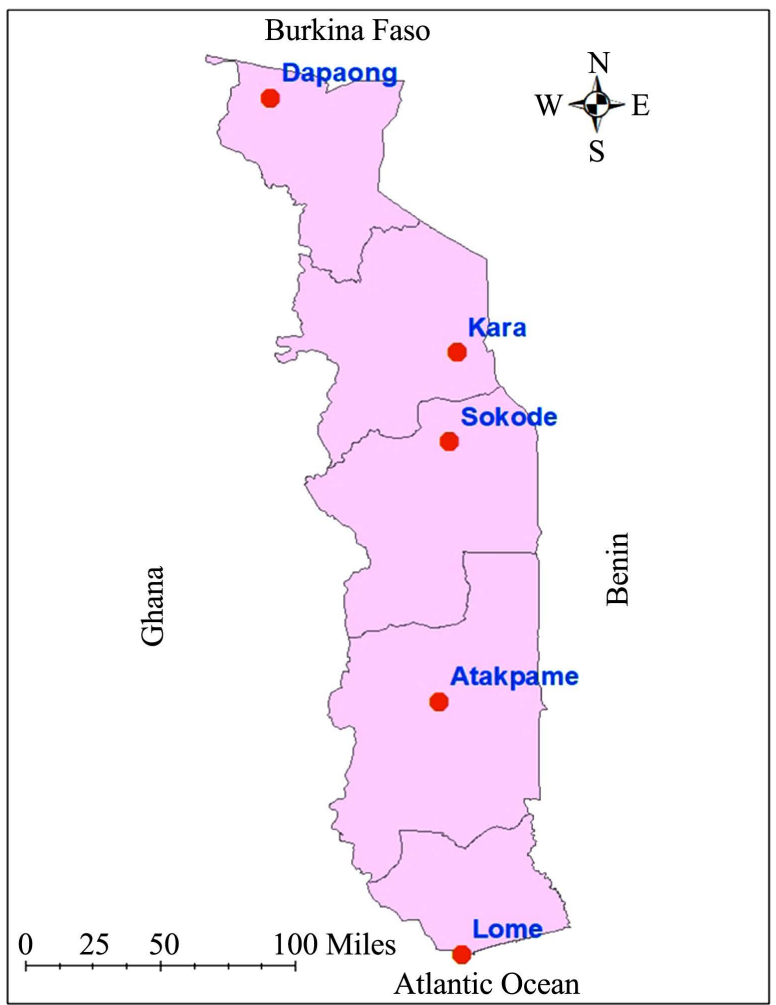

Figure 1. Study cities.

\subsection{Gathering Weather Data for the Five Main Cities in Togo}

Togo is a country located in the northern hemisphere, bordered by the Atlantic Ocean to the south, Burkina Faso to the North, Benin to the East and Ghana to the West. It extends from Lomé to Cinkassé over latitude between 6 and 11 degrees north and a longitude between 1.23 and 0.21 degrees east. For the purposes of this study, we collected data of daily relative humidity, daily mean global solar radiation on horizontal, daily mean temperature and daily sunshine hours along five years (2015-2020), from the General Directorate of National Meteorology of Togo which has a meteorological station in each of the 5 regional capitals concerned by this study, whose geographic coordinates are shown respectively on Table 1. The five towns are the most important cities in the country with a high population and most of industries and commercial activities are located in or close to them. These cities have been selected for this study because existing and planned solar plants which are located near them. We were limited to five years back because of the lack of certain data which does not allow to have well-structured and coherent data.

\subsection{Mathematical Modeling}

Among numerous multivariable linear or nonlinear models existing, there are some which give a good accuracy of solar global horizontal radiation dependent to climatic parameters. These methods, often, were limited by the non-availability of measured data all over some regions. Thus, their performances are sometimes 
Table 1. Geographic coordinates of the study cities.

\begin{tabular}{ccc}
\hline City & Longitude $\left(^{\circ}\right)$ & Latitude $\left(^{\circ}\right)$ \\
\hline Lomé & 1.23 & 6.13 \\
Atakpamé & 1.11 & 7.54 \\
Sokodé & 1.16 & 8.98 \\
Kara & 1.20 & 9.48 \\
Dapaong & 0.21 & 10.90 \\
\hline
\end{tabular}

dependent on the locations and the number of geographic parameters considered [11]. The data collected from General Directorate of National Meteorology of Togo are considered over five years for most significant results. In this study, starting from the analysis of the different models of the literature and in particular those developed in Africa such as those of Ajayi et al. [11] and Amou et al. [12], we developed a model, expressed by Equation (1), which combines linear and nonlinear methods with harmonic and exponential terms to enhance global horizontal solar radiation prediction. The main parameters considered are: location latitude $\varphi$, daily relative humidity $\mathrm{RH}$, daily ratio of sunshine duration $\left(n_{i} / N\right)$, daily mean temperature $T$, and day number in the year $n$.

$$
\begin{aligned}
G_{h}= & a(R H+T) * I_{o} * \sin (\varphi)+b * I_{o} * \exp (c * T) * \cos (\varphi) \\
& +d *\left(n_{i} / N\right)^{2} * \cos (\varphi)+e * T^{2}+f * \cos (\varphi) * \cos (n)+j
\end{aligned}
$$

$I_{o}$ is the solar constant $\left(1367 \mathrm{~W} / \mathrm{m}^{2}\right), n_{i}$ is the sunshine duration, $N$ the day length or maximum sunshine duration. The correlation coefficients $a, b, c, d, e, f$ and $j$ are constants calculated for each location considered.

\subsection{Model Performance and Statistical Errors}

Several statistical indicators allow comparing the solar radiation results from theoretical models to measured data. The performance of models and their accuracy in data prediction are often described by parameters like the Root Mean Square Error (RMSE), the Mean Bias Error (MBE), the Mean Percentage Error (MPE) and the Mean Absolute Percentage Error (MAPE) [16] [17] [18]. Their mathematical well-known expressions are given as follow.

$$
\begin{gathered}
\text { RMSE }=\sqrt{\left(\sum_{i=1}^{n}(G m-G c a l)^{2}\right) / k} \\
\operatorname{MBE}=1 / k *\left(\sum_{i=1}^{n}(G m-G c a l)\right) \\
\operatorname{MPE}=1 / K *\left(\sum_{i=1}^{n}\left(\frac{G m-G c a l}{G m}\right) * 100\right) \\
\operatorname{MAPE}=1 / K *\left(\sum_{i=1}^{n}\left|\left(\frac{G m-G c a l}{G m}\right)\right| * 100\right)
\end{gathered}
$$

where $n=$ number of data points, $G m=$ mean of all the measured global solar radiation, $G c a l=$ calculated daily global solar radiation. The closer these para- 
meters are to zero, the better the model. The MBE can get negative or positive values, meaning that we have respectively underestimation or overestimation of the calculated solar radiations data compared to those measured. The RMSE is always positive and is best when it is as small as possible. Likewise, the MAPE and MPE are indicators which describe the difference between measured and calculated values [19] [20].

\section{Results and Discussion}

The correlation coefficients calculated for each of the five main cities in Togo are presented in Table 2. These independent constants express the best model approach to real data when nonlinear regression has been done for horizontal solar radiation data.

The statistical errors outcome from the model implemented for each city are shown in Table 3 and represent the best values of nonlinear regression. From the MBE values, the model gives overestimation for Atakpamé and underestimation for other cities. All RMSE are positives, we get minimum $\left(20.105689 \mathrm{~W} / \mathrm{m}^{2}\right)$ and maximum $\left(25.2459736 \mathrm{~W} / \mathrm{m}^{2}\right)$ deviations in Atakpamé and Dapaong respectively. The MPE and MAPE respectively decrease or increase from Lomé to Dapaong. These results afford to reveal that the model using in Lomé is most performed than others through the MPE and MAPE values. But taking only the RMSE or MBE, it gives us respectively Dapaong and Atakpamé most accurate from the model prediction.

Table 2. Calculated coefficients for the study model.

\begin{tabular}{cccccc}
\hline $\begin{array}{c}\text { Model } \\
\text { coefficients }\end{array}$ & Lomé & Atakpamé & Sokodé & Kara & Dapaong \\
\hline$a$ & -0.0015993 & -0.0000353 & 0.0005096 & 0.0161266 & 0.0008064 \\
$b$ & 1802830 & 0.3615234 & -0.0947456 & -0.1142607 & -1.1036759 \\
$c$ & -4.2226325 & 0.0704849 & 0.0658425 & -0.0021463 & -0.0007957 \\
$d$ & -5.3509832 & 1412.4584850 & -507.610323 & -447.816994 & -4867.783579 \\
$e$ & 0.1594232 & -1.1641819 & -0.7239317 & 0.1143187 & 0.1211770 \\
$f$ & 0.5945587 & 1.31671427 & 0.0000699 & 0.0000698 & 0.0000698 \\
$j$ & 55.1925940 & 2.6324906 & 0.1130813 & 0.1125114 & 0.1199275 \\
\hline
\end{tabular}

Table 3. Results of performance of the model for the five cities.

\begin{tabular}{cccccc}
\hline $\begin{array}{c}\text { Error terms } \\
\text { of the model }\end{array}$ & Lomé & Atakpamé & Sokodé & Kara & Dapaong \\
\hline MBE & -0.0001872 & 0.0011372 & -0.0026567 & -0.0000508 & -0.0000514 \\
RMSE & 20.3931769 & 20.1056890 & 21.8950090 & 24.7269509 & 25.2459736 \\
MPE & -0.9334437 & -1.3477398 & -1.5249202 & -2.2948975 & -3.1750512 \\
MAPE & 7.7349758 & 8.4669199 & 8.5869980 & 9.9704989 & 10.5069315 \\
\hline
\end{tabular}


In order to test the performance and accuracy of our model compared to other models in the literature, we compared the statistical parameters of our model with those of Amou et al. and Ajayi et al. We have targeted these two models because the model of Amou et al. is the only model on the prediction of the global solar radiation of Togo known in the literature today; and the model of Ajayi et al. meanwhile, is a model that has been applied to the largest country in our sub-region (Nigeria) and above all it has been compared to ten other regional or international models such as: Fagbenle [21], Akpabio et al. [22], Udo (Akpabio et al.) [22], Akinoglu and Ecevit (Akpabio et al. [22]), Ertekin and Yaldiz [23], Akinoglu and Ecevit [24], Yohanna et al. [25], Gopinathan [26], Rietveld [27], Glower and McCulloch [28]. Table 4 presents the results of statistical errors of the different models implemented for each city. From Lomé to Dapaong, we generaly observed that our model parameters values are less than those from both models concerned. The values of MBE, RMSE, MPE, and

Table 4. Results of comparing the model from this study with two other models to determine the model with best fit for the five main cities in Togo.

\begin{tabular}{|c|c|c|c|c|}
\hline $\begin{array}{l}\text { Error term } \\
\text { of model }\end{array}$ & Locations & Model & $\begin{array}{c}\text { Amou et al. } \\
{[15]}\end{array}$ & $\begin{array}{c}\text { Ajayi et al. } \\
{[16]}\end{array}$ \\
\hline MBE & \multirow{4}{*}{ Lomé } & -0.0001872 & 0.00070396 & -0.00054403 \\
\hline RMSE & & 20.3931769 & 21.4905556 & 20.472645 \\
\hline MPE & & -0.93344373 & -1.02406335 & -0.94080837 \\
\hline MAPE & & 7.73497583 & 8.05256909 & 7.67838959 \\
\hline MBE & \multirow{4}{*}{ Atakpamé } & 0.00113721 & 000002.475 & 0.00099474 \\
\hline RMSE & & 20.105689 & 32.7002605 & 29.4214765 \\
\hline MPE & & -1.34773987 & -3.11619532 & -2.59093116 \\
\hline MAPE & & 8.4669199 & 14.0566856 & 12.4730265 \\
\hline MBE & \multirow{4}{*}{ Sokodé } & -0.00265673 & 0.00545191 & 0.00010889 \\
\hline RMSE & & 21.895009 & 32.2882313 & 30.0782985 \\
\hline MPE & & -1.52492023 & -2.72929591 & -2.64398625 \\
\hline MAPE & & 8.58699803 & 13.1228199 & 12.1765105 \\
\hline MBE & \multirow{4}{*}{ Kara } & -000005.0831 & -00000007.3905 & -0.0015014 \\
\hline RMSE & & 24,7269509 & 34,2080588 & 32.9304318 \\
\hline MPE & & -2.29489755 & -3.86642421 & -3.66306766 \\
\hline MAPE & & 9.97049893 & 14.4054242 & 13.73233 \\
\hline MBE & \multirow{4}{*}{ Dapaong } & -000005.1457 & -00000002.2113 & -0.00034491 \\
\hline RMSE & & 25.2459736 & 36.9080284 & 36.7547407 \\
\hline MPE & & -3.17505127 & -5.2197335 & -5.23816491 \\
\hline MAPE & & 10.5069315 & 15.7789468 & 15.8406344 \\
\hline
\end{tabular}


MAPE clearly show that the best performance is given by our model followed by Ajayi et al. [16] over the five cities. This can be more illustrated with Figure 2, even though these values increase from Lomé to Dapaong, our model keeps the best performance to predict global horizontal solar radiation data.

Further to this, Figures 3-7 shows comparison between estimated data from our model and measured data of daily horizontal solar radiation for the five cities in Togo. It can be seen the proximity of the values predicted by our model and the measured data.

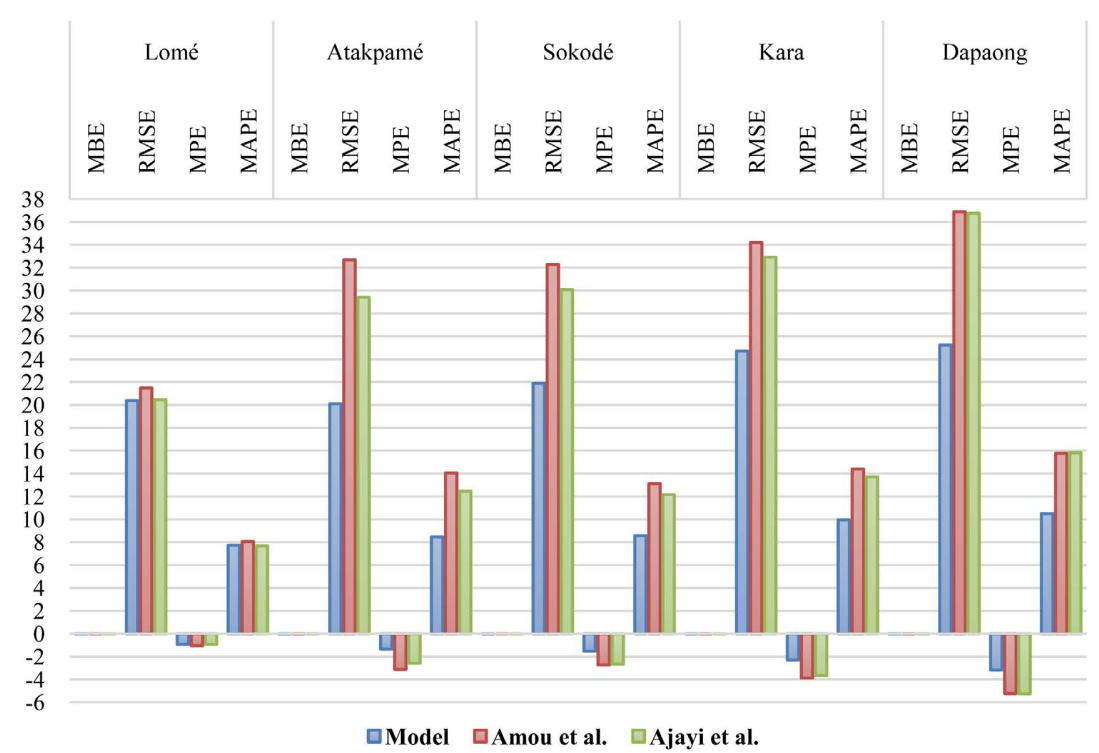

Figure 2. Comparison of statistical errors form our model and two other models for the five main cities in Togo.

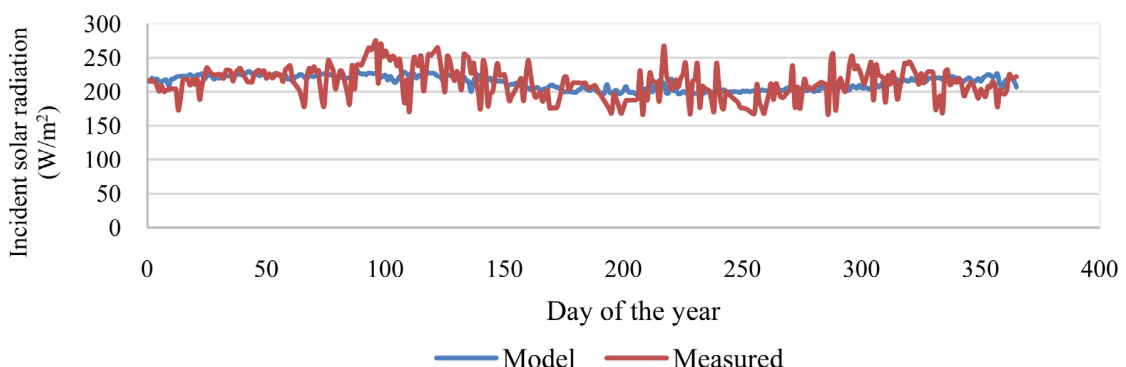

Figure 3. Comparison of estimated and measured data for Lomé.

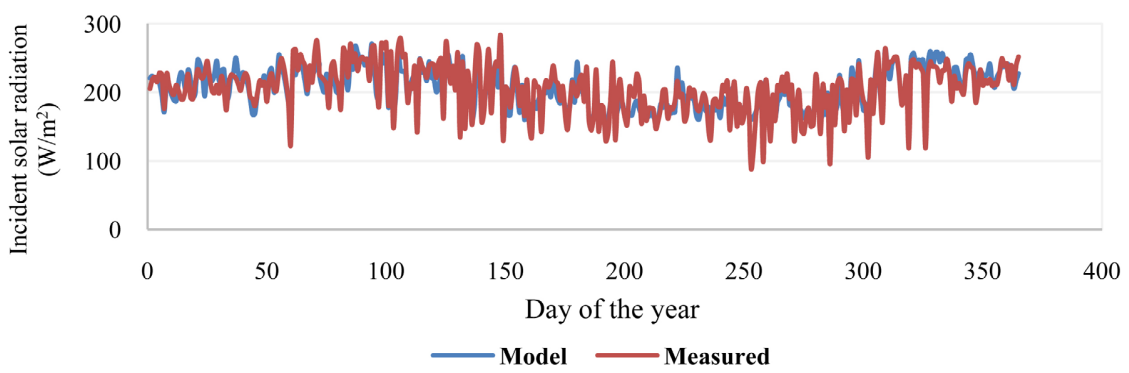

Figure 4. Comparison of estimated and measured data for Atakpamé. 


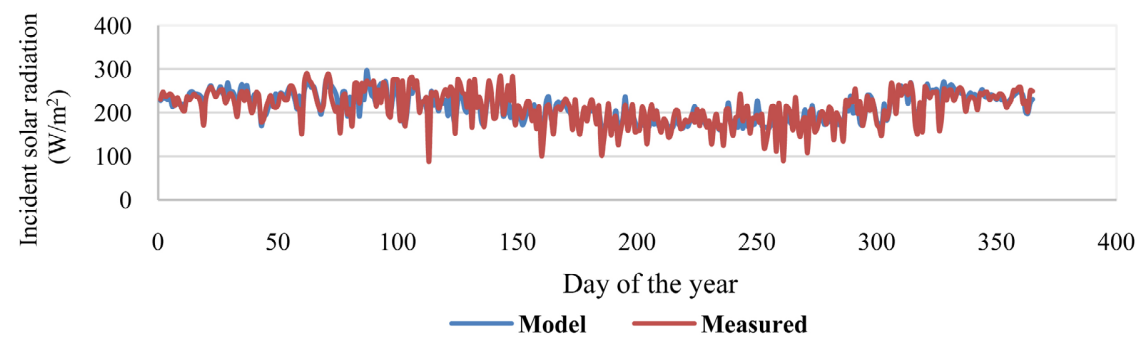

Figure 5. Comparison of estimated and measured data for Sokodé.

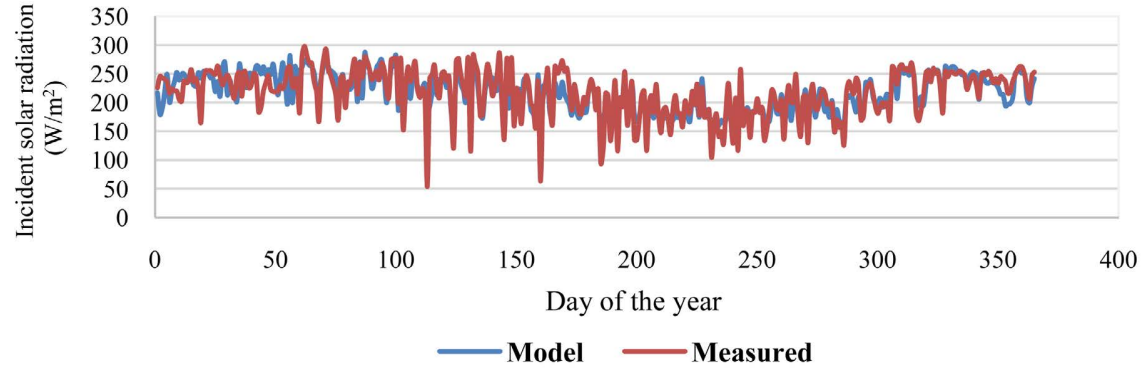

Figure 6. Comparison of estimated and measured data for Kara.

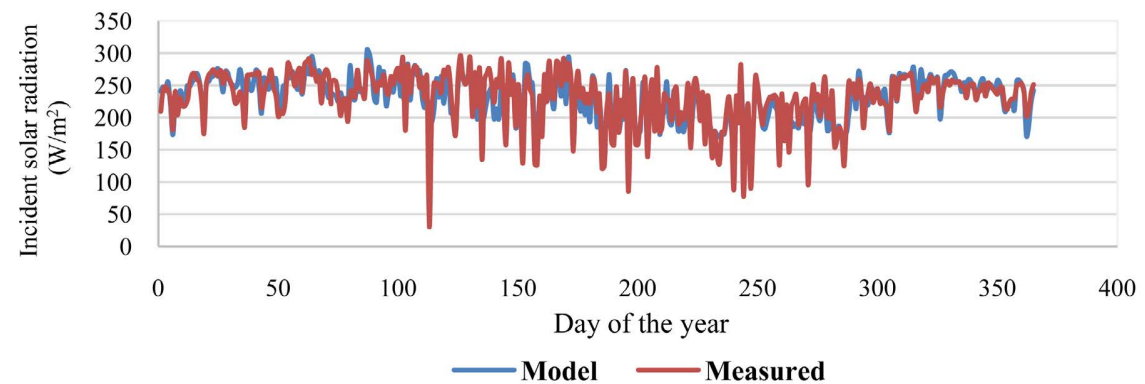

Figure 7. Comparison of estimated and measured data for Dapaong.

\section{Conclusions}

For handling solar technology and getting a useful operating efficiency, the availability of solar radiation data requires to have a good assessment of solar potential anywhere. Due to the weak spread of meteorological stations for measuring the daily horizontal solar radiation, previous studies through linear or nonlinear regressions, taking into account climate parameters, tried to predict solar data with an acceptable accuracy of no more than $10 \%$ of statistical error.

In this study, we developed a new model, combining nonlinear and linear models with harmonic and exponential terms to enhance the data prediction in Togo, taking into account parameters like location latitude, daily relative humidity, daily ratio of sunshine duration, daily mean temperature and day number in the year. The results revealed that our model is the most efficient, compared to the models of Amou et al. and Ajayi et al., to predict global horizontal solar radiation over the five main cities in Togo. Further, this model could be employed for predicting daily global horizontal solar radiation of other similar climatic locations inside or outside of Togo. 
Unavailability of observation weather data for a long term to validate the present developed model is a limitation of the work. In the future, the model could be used on larger data, over at least 30 years, in order to evaluate its accuracy over long periods.

\section{Conflicts of Interest}

The authors declare no conflicts of interest regarding the publication of this paper.

\section{References}

[1] Bailek, N., Bouchouicha, K., El-Shimy, M., Slimani, A., Chang, K.-C. and Djaafari, A. (2017) Improved Mathematical Modeling of the Hourly Solar Diffuse Fraction (HSDF)-Adrar, Algeria Case Study. International Journal of Mathematical Analysis and Applications, 4, 8-12.

[2] Jamil, B. and Akhtar, N. (2017) Estimation of Diffuse Solar Radiation in Humid-Subtropical Climatic Region of India: Comparison of Diffuse Fraction and Diffusion Coefficient Models. Energy, 131, 149-164.

https://doi.org/10.1016/j.energy.2017.05.018

[3] Bailek, N., Bouchouicha, K., Abdel-Hadi, Y.A., El-Shimy, M., Slimani, A., Jamil, B. and Djaafari, A. (2020) Developing a New Model for Predicting Global Solar Radiation on a Horizontal Surface Located in Southwest Region of Algeria. NRIAG Journal of Astronomy and Geophysics, 9, 341-349.

https://doi.org/10.1080/20909977.2020.1746892

[4] Angstrom, A. (1924) Solar and Terrestrial Radiation. Quarterly Journal of the Royal Meteorological Society, 50, 121-126. https://doi.org/10.1002/qj.49705021008

[5] Prescott, J.A. (1940) Evaporation from a Water Surface in Relation to Solar Radiation. Transactions of the Royal Society of South Australia, 64, 114-118.

[6] Kamel, M.A., Shalaby, S.A. and Mostafa, S.S. (1993) Solar Radiation over Egypt: Comparison of Predicted and Measured Meteorological Data. Solar Energy, 50, 463-467. https://doi.org/10.1016/0038-092X(93)90106-X

[7] Tadros, M.T.Y. (2000) Uses of Sunshine Duration to Estimate the Global Solar Radiation over Eight Meteorological Stations in Egypt. Renewable Energy, 21, 231-246. https://doi.org/10.1016/S0960-1481(00)00009-4

[8] Ezekwe, C.I. and Ezeilo Clifford, C.O. (1981) Measured Solar Radiation in a Nigerian Environment Compared with Predicted Data. Solar Energy, 26, 181-186. https://doi.org/10.1016/0038-092X(81)90083-9

[9] Khogali, A. (1983) Solar Radiation over Sudan-Comparison of Measured and Predicted Data. Solar Energy, 31, 41-53. https://doi.org/10.1016/0038-092X(83)90032-4

[10] Gopinathan, K.K. (1992) Estimation of Hourly Global and Diffuse Solar Radiation from Hourly Sunshine Duration. Solar Energy, 48, 3-5. https://doi.org/10.1016/0038-092X(92)90170-F

[11] Ajayi, O.O., Ohijeagbon, O.D., Nwadialo, C.E. and Olasope, O. (2014) New Model to Estimate Daily Global Solar Radiation over Nigeria. Sustainable Energy Technologies and Assessments, 5, 28-36. https://doi.org/10.1016/j.seta.2013.11.001

[12] Amou, K.A., Sagna, K., Lare, Y. and Napo, K. (2017) Modeling of the Solar Potential of Lomé, Atakpamé and Mango from Weather Data in TOGO. Renewable Energy Research, 2, 22-26. https://doi.org/10.11648/j.sjee.20170503.11 
[13] Ojosu, J.O. and Komolafe, L.K. (1987) Models for Estimating Solar Radiation Availability in South Western Nigeria. Nigerian Journal of Solar Energy, 7, 69-77.

[14] Ertekin, C. and Yaldiz, O. (2000) Comparison of Some Existing Models for Estimating Global Solar Radiation for Antalya (Turkey). Energy Conversion and Management, 41, 311-330. https://doi.org/10.1016/S0196-8904(99)00127-2

[15] Amou, K.A., Boroze, T.T.-E., Ouro-Djobo, S., Sagna, K., Azouma, Y.O., Banna, M. and Napo, K. (2017) An Application of the Multilayer Perceptron: Estimation of Global Solar Radiation and the Establishment of Solar Radiation Maps of Togo. Sustainable Energy, 5, 6-15. https://doi.org/10.12691/rse-5-1-2

[16] Ajayi, O.O., Fagbenle, R.O. and Katende, J. (2011) Assessment of Wind Power Potential and Wind Electricity Generation Using WECS of Two Sites in South West, Nigeria. International Journal of Energy Science, 1, 78-92.

[17] Ajayi, O.O., Fagbenle, R.O., Katende, J., Okeniyi, J.O. and Omotosho, O.A. (2010) Wind Energy Potential for Power Generation of a Local Site in Gusau, Nigeria. International Journal of Energy for a Clean Environment, 11, 99-116. https://doi.org/10.1615/InterJEnerCleanEnv.2011003309

[18] Ajayi, O.O., Fagbenle, R.O. and Katende, J. (2011) Wind Profile Characteristics and Econometric Analysis of Wind Power Generation of a Site in Sokoto State, Nigeria. Energy Science and Technology, 1, 54-66.

[19] Khatiba, T., Mohameda, A. and Sopianb, K. (2012) A Review of Solar Energy Modeling Techniques. Renewable and Sustainable Energy Reviews, 16, 2864-2869.

https://doi.org/10.1016/j.rser.2012.01.064

[20] El Mghouchi, Y., El Bouardi, A., Choulli, Z. and Ajzoul, T. (2014) New Model to Estimate and Evaluate the Solar Radiation. International Journal of Sustainable Built Environment, 3, 225-234. https://doi.org/10.1016/j.ijsbe.2014.11.001

[21] Fagbenle, R.L. (1993) Total Solar Radiation Estimates in Nigeria Using a Maximum Likelihood Quadratic Fit. Renewable Energy, 3, 813-817. https://doi.org/10.1016/0960-1481(93)90089-Y

[22] Akpabio, L.E., Udo, S.O. and Etuk, S.E. (2005) Modelling Global Solar Radiation for a Tropical Location: Onne, Nigeria. Turkish Journal of Physics, 29, 63-68.

[23] Ertekin, C. and Yaldiz, O. (2000) Comparison of Existing Models for Estimating Global Solar Radiation for Antaya (Turkey). Energy Conversion and Management, 41, 311-330. https://doi.org/10.1016/S0196-8904(99)00127-2

[24] Akinoglu, B.G. and Ecevit, A. (1990) A Further Comparison and Discussion of Sunshine Based Models to Estimate Global Solar Radiation. Solar Energy, 15, 865-872. https://doi.org/10.1016/0360-5442(90)90068-D

[25] Yohanna, J.K., Itodo, I.N. and Umogbai, V.I. (2011) A Model for Determining the Global Solar Radiation for Makurdi, Nigeria. Renewable Energy, 36, 1989-1992. https://doi.org/10.1016/j.renene.2010.12.028

[26] Gopinathan, K.K. (1988) A General Formula for Computing the Coefficients of the Correlations Connecting Global Solar Radiation to Sunshine Duration. Solar Energy, 41, 499-502. https://doi.org/10.1016/0038-092X(88)90052-7

[27] Rietveld, M.R. (1978) A New Method for Estimating the Regression Coefficients in the Formula Relating Solar Radiation to Sunshine. Agricultural Meteorology, 19, 243-252. https://doi.org/10.1016/0002-1571(78)90014-6

[28] Glower, J. and Mcgulloch, J.S.G. (1958) The Empirical Relation between Solar Radiation and Hours of Sunshine. Quarterly Journal of the Royal Meteorological Society, 84, 172-175. https://doi.org/10.1002/qj.49708436011 